\title{
SEGURIDADE SOCIAL E PROTEÇÃO À MULHER NA CONSTITUINTE DE 1988: NARRATIVAS SOBRE AS DISPUTAS E SENTIDOS A PARTIR DO DIREITO DE APOSENTADORIA
}

\author{
AUTOR: JAQUELINE BARROS SANTOS \\ CO-AUTOR/ORIENTADOR: VICTOR HUGO CRISCUOLO BOSON
}

Resumo: O presente trabalho buscou analisar as disputas envolvendo o direito à aposentadoria da mulher na Constituinte de 1987-1988. Para tanto, realizou-se a análise dos anais da Assembleia Nacional Constituinte (ANC), especificamente as atas de reuniões da Subcomissão dos Direitos dos Trabalhadores e Servidores Públicos. Dessa forma, foi possível analisar os principais debates e as principais demandas dos diversos segmentos de trabalhadores e trabalhadoras. Foi possível também analisar os posicionamentos das entidades convocadas a participar na dinâmica das atividades legislativas e a colaborar com os debates articulados com vistas ao futuro texto constitucional. Apesar da pouca representatividade em número de mulheres na ANC, podemos concluir que, não obstante as resistências, pautas importantes foram discutidas, como o exercício de profissões vedadas às mulheres (caso da profissão de pescadora), a previsibilidade expressa da licença maternidade e o direito à aposentadoria da mulher com critérios próprios, Observando-se as especificidades, houve nesse sentido a recepção de indicadores de gênero para a afirmação de direitos sociais, atentos às desigualdades de grupos historicamente vulnerabilizados e discriminados. O trabalho desenvolvido pela Assembleia Nacional Constituinte, e especificamente pela Subcomissão dos Direitos dos Trabalhadores e Servidores Públicos, demonstrou uma preocupação na consolidação dos direitos dos trabalhadores e das trabalhadoras, em vários âmbitos, considerando a existência de contextos diferentes de trabalhadores e trabalhadoras no Brasil. Algumas dessas pautas, como as relativas à licença maternidade, à não discriminação no mercado de trabalho por razões de sexo e à aposentadoria, foram veiculadas textualmente pela Constituição da República Federativa do Brasil de 1988.

Palavras-chave: Assembleia Nacional Constituinte, disputas, aposentadoria, mulher. 